\title{
Smart infrastructure: an emerging frontier for multidisciplinary research
}

1 Robert Ighodaro Ogie MSC

Associate Research Fellow, Smart Infrastructure Facility, University of Wollongong, Wollongong, Australia (corresponding author: rogie@uow.edu.au) (Orcid:0000-0002-6476-2309)
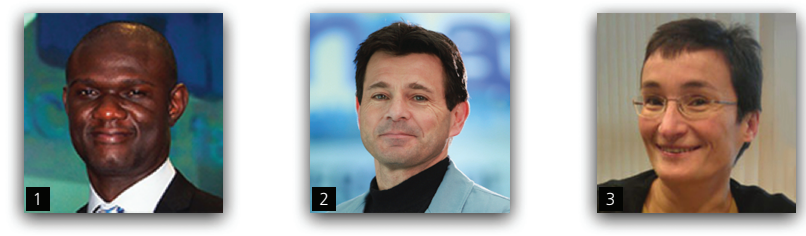

2 Pascal Perez PhD

Director, Smart Infrastructure Facility, University of Wollongong, Wollongong, Australia

3 Virginia Dignum PhD

Associate Professor, Faculty of Technology, Policy and Management, Delft University of Technology, Delft, the Netherlands

The irreversible marriage between digital technology and physical urban infrastructure has given rise to the concept of smart infrastructure. The potential benefits of smart infrastructure are significant; however, their realisation will depend on society's ability to address pressing issues, such as the need to develop a common language to describe terms and processes. This paper aims to lay out the foundations of such a common language. First, the authors review academic literature in order to outline key characteristics of so-called smart infrastructure systems. Importantly, the authors define and differentiate between smart and intelligent infrastructure systems. Then, the authors use an LVP framework to describe the levels $(L)$, values $(V)$ and principles $(P)$ of inherently smart infrastructure systems. Finally, the authors argue that the study of smart infrastructure is a multidisciplinary field of research that reaches beyond traditional engineering and information technology disciplines. The authors expect that eliminating ambiguity and fragmentation in the definition of smart infrastructure systems will enhance research on and practice of these systems.

\section{Introduction}

Infrastructure systems such as water distribution networks, electricity grids, communication webs and transport infrastructure constitute the foundation of modern societies. They provide the basis for everyday life and enable the flow of goods, information and services within urban and regional settings (Rice et al., 2010). As society moves deeper into the twenty-first century, the societal demand on infrastructure assets is growing rapidly, with high expectations in terms of productivity and service delivery (Annaswamy et al., 2016; Fang et al., 2012). This quest for more efficient infrastructure associated with the rise of information technology (IT) has led to the concept of 'smart infrastructure', wherein enabling technologies such as connected sensors and big data analytics are integrated with physical infrastructure in order to achieve real-time monitoring, efficient decision-making and enhanced service delivery (Weiss, 2009). The potential benefits of smart infrastructure include decreased maintenance costs, reduced damage and disruption costs (traffic congestion or power blackout), increased quality and value of service (on-demand use and flexible tariffs), as well as protecting human life (less road accidents or better response to disasters); all these benefits contribute to sustainable urban growth (Morimoto, 2010). Over the years, the concept of smart infrastructure has been applied in several areas, including electricity distribution, water and waste water services, automatic toll collection, intelligent transport systems, emergency services and the monitoring of critical infrastructure assets such as tunnels, bridges and dams (Hoult et al., 2009; Li, 2010; Venkatasubramanian et al., 2014).

Although the benefits of smart infrastructure are potentially significant, their realisation will depend on society's ability to address pressing issues, such as the need to develop a common language of terms and processes (CSIC, 2016a). In fact, the very term 'smart infrastructure' is being used in various contexts to describe different sociotechnical settings. According to Hagen (2011), there is no common definition to describe a smart infrastructure, let alone to design or build it. This lack of standardisation makes room for ambiguity, loose interpretations and loss of meaning, as was previously the case with concepts such as 'sustainable development' (Buckman et al., 2014). Case-based fragmentation and semantic ambiguity are reinforced by a strong marketing drive imposed by the IT industry for which everything has to be smart, from sensors to cities. This lack of clarity has already started impacting smart infrastructure projects as expectations from asset owners or operators are dashed by technology-driven implementation of so-called smart solutions (Buckman et al., 2014).

To address this issue, the authors have reviewed academic and grey literature between 1990 and 2016 and attempted to present a comprehensive definition of the term 'smart infrastructure'. 
Smart infrastructure: an emerging

frontier for multidisciplinary research

Ogie, Perez and Dignum
Importantly, the authors sought to differentiate between 'smart' and 'intelligent' infrastructure. Then, the authors use an LVP framework to describe the levels (L), values (V) and principles (P) of smart infrastructure systems. Finally, the authors advocate for a multidisciplinary approach to studies on and design of smart infrastructure systems, reaching beyond traditional engineering and IT disciplines.

\section{What is a smart infrastructure?}

\subsection{Self-monitoring against self-awareness}

According to Weiss (2009), a smart infrastructure is a lens through which the future is seen. It is about self-driving cars that recognise one another, bridges that detect their own weaknesses, power grids that exchange data with home appliances, in short, all cyberphysical infrastructure systems that make cities smart (Weiss, 2009). From the perspective of smart cities, Alkandari et al. (2012) describe smart infrastructure as the backbone of a city, driven by a wireless sensor network. Similarly, studies on electricity grids describe smart infrastructure as the backbone of the distribution grid made of a smart energy subsystem, a smart information subsystem and a smart communication subsystem that all work together to deliver desirable outcomes such as improved adaptability, longevity and efficiency of services provided to consumers and businesses (Guizani and Anan, 2014).

In the context of a global, knowledge-driven economy, the term 'smart infrastructure' is often used to represent three strategic elements, namely, individual knowledge, intellectual property and social networking; the mixture of which determines the competitive advantage for becoming the leader in an organisation or an industry (Raluca, 2013). Similarly, Lee and Gibson (2002) relate smart infrastructure to talent, technology, capital and know-how that combine to strongly influence the development and sustainability of the world's leading technopoles (see also Gibson and Stiles (2000)).

In addition, there is a trend in the literature to define smart infrastructure as a transitioning process from a state of 'dumbness' to a state of 'intelligence'. In this context, a dumb infrastructure is not able to communicate, adapt to changing needs and connect to a larger network, whereas a smart infrastructure can improve performance by responding purposefully to changes in its environment, including demands from users as well as from other assets (Royal Academy of Engineering, 2012; Weiss, 2009). According to Kadam (2013), a smart infrastructure is an existing infrastructure that has been transitioned to a regime of major, positive changes in infrastructure service delivery due to the adoption of technological innovations.

From that perspective, the key issue is to link a degree of innovation with a level of smartness. Without this relationship, there is a risk to define loosely smart infrastructure as any association of technology with physical infrastructure. For example, using information and communication technologies (ICTs) to help with the management of power distribution assets or the maintenance of bridges and tunnels is often tagged as a 'smart' deployment without more scrutiny (Alusi et al., 2011; Fujii et al., 2013). More recently, Liu et al. (2014) specify that ICT solutions have to be ubiquitous in nature (e.g. cloud computing and the Internet of things) in order to qualify as smart infrastructure. Other technologies associated with smart infrastructure include building information modelling, geographic information systems, artificial intelligence (AI) (including machine learning) and enabling technologies such as optic fibre, wireless sensor networks or low-power microelectromechanical systems (Memss) that facilitate real-time data acquisition and processing (Liu and Tomizuka, 2003). According to Engineers Australia (2015), a specific feature of smart infrastructure systems is the continuous collection of a large volume of information to be analysed and fed back into the system's operation to improve performance.

At the most basic level, a smart infrastructure can be defined as an interconnected sensing network that provides real-time digital information about the state of the system (Morimoto, 2010). This definition of smart infrastructure focuses on the self-monitoring ability of the system through the combination of physical assets and digital technology (Balakrishna, 2012; Shahzadi et al., 2013; Stefansson and Lumsden, 2008). In this context, digital technologies are used to acquire data that are then processed, stored and delivered in the form of reliable and actionable information to aid infrastructure providers in making informed decisions about the management of their infrastructure assets (Hagen, 2011). Cambridge Centre for Smart Infrastructure and Construction (CSIC, 2016a: p. 2) defines smart infrastructure as the result of combining physical infrastructure with digital infrastructure, providing improved information to enable better decision making, faster and cheaper'. Some authors use the word 'digital' interchangeably with the word 'cyber'; hence, it is common to represent smart infrastructures as cyberphysical systems (Annaswamy et al., 2016; Dillon et al., 2011).

Self-awareness constitutes the next level of smartness, whereby an infrastructure system uses monitoring information in order to respond to changing conditions (El-Diraby, 2003; El-Diraby and Rasic, 2004) or report back on its internal structural and material health (Burgy and Garrett, 2002). More recently, Annaswamy et al. (2016) proposed a bolder definition wherein a smart infrastructure has the ability to self-govern or to make decisions without human interventions. More precisely, the authors define a smart infrastructure as one that is able to monitor itself, communicate and, most importantly, self-govern. In practice, this infrastructure initiates its own condition-based maintenance in order to limit time and reduce operational overheads. Similarly, CSIC (2016b: p. 9) describes a smart infrastructure as one that 'has the ability to influence and direct its own use, maintenance and support by responding intelligently to changes in its environment'. But how much control should be given to an infrastructure in order to satisfy the smartness criteria?

\subsection{Intelligent against smart infrastructure}

There is a lot of confusion as to how the term 'smart' is different from 'intelligent' when used to describe physical assets such as 
Smart Infrastructure and Construction

Volume 170 Issue SC1
Smart infrastructure: an emerging

frontier for multidisciplinary research

Ogie, Perez and Dignum buildings or utility networks (Buckman et al., 2014). The authors' literature review indicates that intelligent infrastructure (Aktan et al., 1998; Gershenfeld et al., 2010; Le et al., 2015; Wu and Fujino, 2005) and smart infrastructure (Feng et al., 1995; Hoult et al., 2009; Klar et al., 2016) have both been actively researched for many decades. While Negrete-Martínez (2008) arbitrarily argues that intelligent systems are those with the greatest degree of smartness, as it is the case for smart infrastructure, there is no consensual definition of an intelligent infrastructure either (Aktan et al., 1998).

According to Dadashi et al. (2011), intelligence in the context of physical assets refers to timely decision support that helps human operators to achieve safer, more reliable, relevant and efficient outcomes; an intelligent infrastructure is the architecture that enables the emergence of such intelligence. Similarly, Prasad and Ruggieri (2014) note that intelligent infrastructure is all about capturing and analysing data in order to drive efficiency through autonomic responses. One of the oldest and yet most comprehensive definitions of intelligent infrastructure was proposed by Aktan et al. (1998: p. 675): an integrated package of physical infrastructure and a sensor-based monitoring system (with control and communication functions) that has the ability to '(a) sense its loading environment, as well as its own responses and any ongoing deterioration and damage; (b) reason by assessing its condition, health, capacity and performance needs and the actual performance that is being delivered; (c) communicate through proper interfaces with other components and systems, including human managers; (d) learn from experience as well as by interfacing with humans for heuristic and mechanistic knowledge; (e) decide and take action for alerting officials, diverting users, structural control, self-repair, closure'.

Comparing these definitions with those presented in Section 2.1, the distinction between intelligent and smart infrastructure has not become clearer. For this reason, some authors maintain that in the context of describing physical assets, the terms 'smart' and 'intelligent' connote the same meaning and can therefore be used interchangeably (Fang et al., 2012; Kadam, 2013). A Google Scholar search on the academic usage of the terms 'intelligent infrastructure' and 'smart infrastructure' has produced the results shown in Table 1 and Figure 1. Results indicate that both terms

Table 1. Academic usage of the terms 'smart infrastructure' and 'intelligent infrastructure' from Google Scholar search engine

\begin{tabular}{|lcc|} 
Period & $\begin{array}{c}\text { Number of articles } \\
\text { using 'intelligent } \\
\text { infrastructure' }\end{array}$ & $\begin{array}{c}\text { Number of articles } \\
\text { using 'smart } \\
\text { infrastructure' }\end{array}$ \\
\hline Prior to 2000 & 157 & 77 \\
2000-2001 & 119 & 23 \\
2002-2003 & 325 & 64 \\
$2004-2005$ & 440 & 78 \\
$2006-2007$ & 651 & 115 \\
$2008-2009$ & 706 & 180 \\
$2010-2011$ & 889 & 379 \\
$2012-2013$ & 1070 & 617 \\
2014-2015 & 1070 & 1020 \\
2016-2017* & 456 & 642 \\
Total & 5883 & 3195 \\
\hline
\end{tabular}

* Still within first quarter of the year.

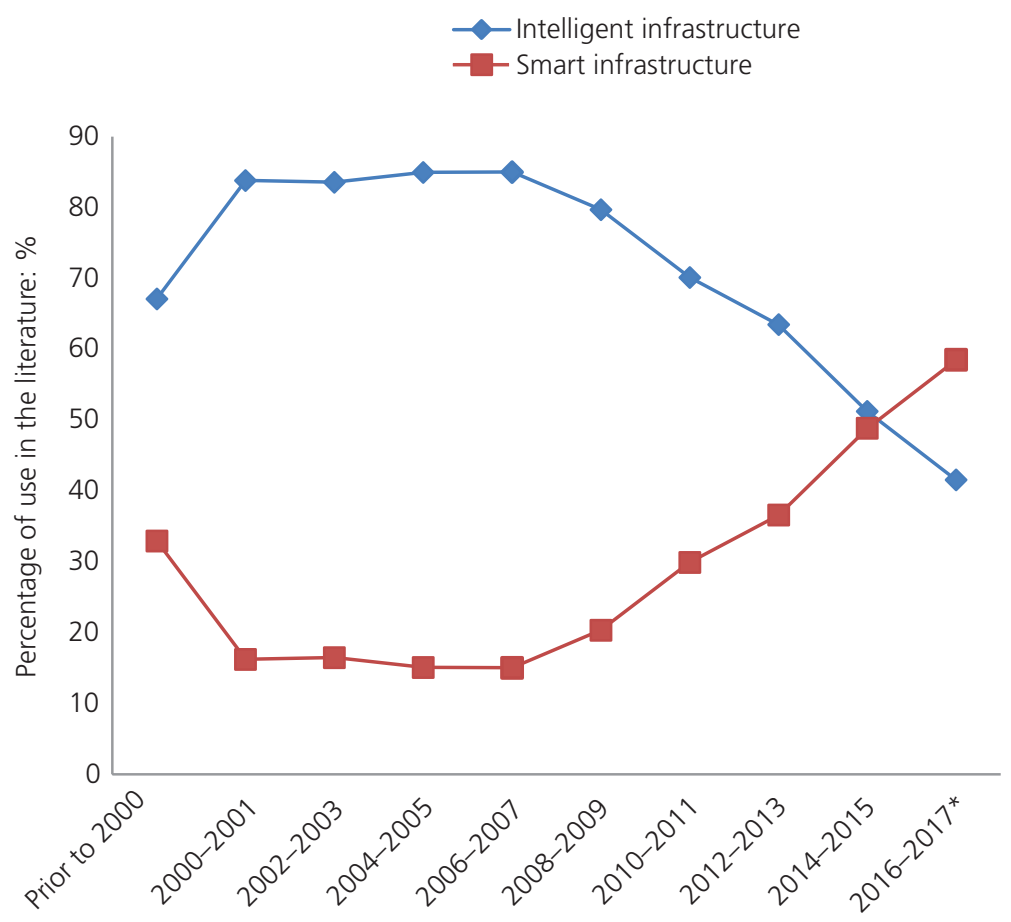

Figure 1. Academic usage of the terms 'smart infrastructure' and 'intelligent infrastructure' (in \%). * Still within first quarter of the year. 
have been used over the last few decades, with intelligent infrastructure used more frequently (5883 instances against 3195 for smart infrastructure). However, Figure 1 clearly shows a sharp increase in the use of 'smart infrastructure' from 2008 to 2009, overtaking the term 'intelligent infrastructure' in 2014-2015. One obvious reason for this shift is the frequent association of recent technological innovation with the word 'smart' during that period (e.g. smart metering, smartphone, smart television, smart home and - naturally - smart city). This confusing mix between technological innovation, marketing strategies and vernacular language had already reached paroxysmal heights with the release of the first iMac 10 years earlier (1998) and its endless list of derivatives, clones and emulators (iPhone, iPod, iSee or even i30). The ' $i$ ' in iMac never meant 'intelligent'; it stood for 'Internet, individual, inform, instruct and inspire'. Ironically, Hyundai's ' $\mathrm{i}$ ' now stands for 'inspiration, intelligence and innovation'.

In the context of the building industry, Buckman et al. (2014) attempt to differentiate between terminologies by arguing that built structures have progressed from being primitive to simple, then automated, then intelligent and finally smart. According to this typology, primitive structures are ordinary physical constructions without any controls; simple structures have controls that are operated manually; automated structures have controls that are operated automatically from a central location; intelligent structures have controls that are operated automatically, with additional sensor-enhanced capability to adjust operations to suit user needs in real time; while smart structures are simply intelligent structures that provide a broader range of automated services that can scale gracefully to better adapt to both user and environmental conditions (Hoy, 2016). In other words, the main distinction is that, unlike intelligent structures that are reactive in exercising their control functions, smart structures are more adaptive, better able to handle issues of fragmentation and interoperability in the use of information and robust enough to dynamically adjust its built form to accommodate changes in use as well as environmental conditions (Buckman et al., 2014). Henceforth, developing intelligent buildings will focus on increasing their self-monitoring and data acquisition capacity, as well as their ability to transform the acquired data into timely, accurate and relevant information for human operators. Developing smart buildings will aim at increasing their autonomous ability to apply acquired and processed data to adaptive improvement of their (energy) efficiency, safety and reliability even as their usage and environmental conditions change. Obviously, an intelligent building can be retrofitted and upgraded to become a smart one.

\subsection{LVP framework for smart infrastructure}

The proposed LVP framework refers to levels (L), values (V) and principles (P). The LVP framework aims to provide a formal and replicable typology to classify, compare and benchmark smart infrastructure initiatives. This is particularly important considering that the technologies on which smart infrastructures are built are constantly changing and what was accepted as a smart system a decade ago may no longer satisfy the conditions of today's standards (Buckman et al., 2014). Hence, as technological innovations and societal demands keep pushing the limits of what is acceptable as a smart system, the LVP framework will provide a common reference point for gauging stakeholders' expectations in smart infrastructure initiatives and how that may be changing over time (Buckman et al., 2014). In other words, significant changes to LVPs of smart infrastructure will provide an indication of how stakeholders' expectations are initially shaped and how they evolve with technological innovations and societal demands. A diagrammatic representation of the LVP framework is shown in Figure 2.

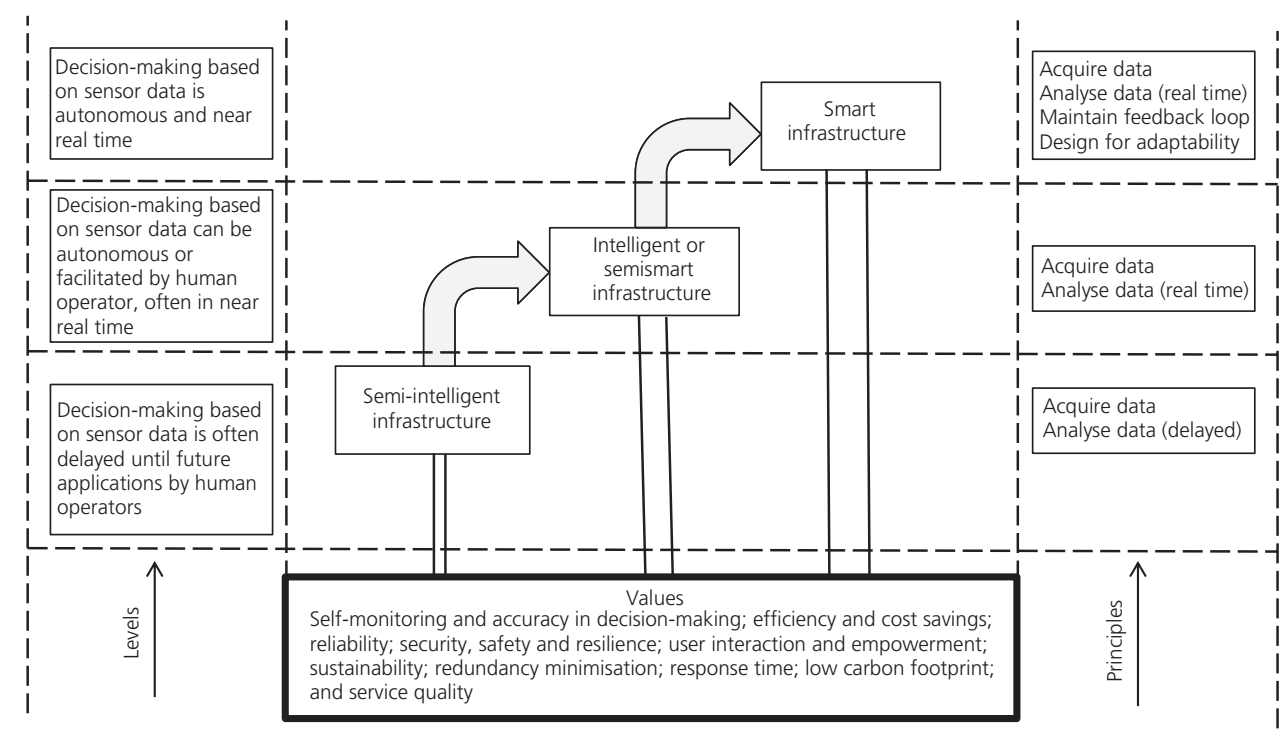

Figure 2. Diagrammatic representation of the LVP framework 
Smart Infrastructure and Construction

Volume 170 Issue SC1
Smart infrastructure: an emerging

frontier for multidisciplinary research

Ogie, Perez and Dignum

\subsubsection{Levels of smart infrastructure}

The Royal Academy of Engineering (2012) noted that smart infrastructure can be defined according to the level of control given to the smart infrastructure (or, conversely, the degree of human involvement in the decision-making process).

(a) Semi-intelligent infrastructure: This is an infrastructure that collects and logs data about its own usage, structural performance, environmental conditions and so on without any ability to make decisions based on the acquired data (Royal Academy of Engineering, 2012). Often, the acquired data are used in the future to improve efficiency and other desirable infrastructure outcomes (Royal Academy of Engineering, 2012).

(b) Intelligent or semismart infrastructure: This is an infrastructure that collects and processes the data into realtime actionable information, which is then used by itself or a human operator in making optimal decisions (Royal Academy of Engineering, 2012). An example of a semismart or intelligent infrastructure is the traffic system that detects road congestion and consequently informs drivers, who may then take appropriate decisions accordingly (Royal Academy of Engineering, 2012).

(c) Smart infrastructure: This is an infrastructure that collects data; processes the data; and takes appropriate actions in a manner that is completely autonomous, dynamic and most importantly adaptive to changing conditions. It is common to find smart grids, smart buildings and smart civil infrastructure falling into this category (Elmenreich and Egarter, 2012).

\subsubsection{Values of smart infrastructure}

Based on relevant references from the authors' literature review (e.g. Annaswamy et al. (2016), Fang et al. (2012), Hagen (2011), Morimoto (2010)), the values that drive a smart infrastructure initiative are synthesised as follows.

(a) Self-monitoring and accuracy in decision making: This involves the ability to self-monitor internal structural and material health as well as environmental and usage conditions in order to improve the accuracy and timeliness of decision making (e.g. predictive maintenance, self-initiation of condition-based maintenance and autodetection of specific faulty parts, thereby avoiding unnecessary ground digging).

(b) Efficiency and cost savings: This entails reducing operational overhead and saving costs by accomplishing more with less.

(c) Reliability: This involves minimising down-time, service failure or disruption.

(d) Security, safety and resilience: This involves maintaining adaptive processes and designs that keep infrastructure and its users safe, secure and resilient to both manmade and natural hazards.

(e) User interaction and empowerment: This involves improving user experience and providing services that are adaptive to the changing needs of consumers.

$(f)$ Sustainability: This involves optimising decision making to ensure sustainable use of resources. (g) Redundancy minimisation: This involves minimising redundant components in the system, thereby saving energy cost and making more resources available for other important purposes.

(h) Response time: This involves early detection and response to time-critical events such as failures, external threats and urgent preventative maintenance.

(i) Low carbon dioxide footprint ('carbon footprint'): This entails minimising greenhouse gas (GHG) emissions and energy consumption.

( $j$ ) Service quality: This entails improving the quality and range of services provided by an infrastructure in order to attain better quality of life, social outcomes and economic productivity.

\subsubsection{Principles of smart infrastructure}

Certain basic principles nourish the design and construction of smart infrastructure (Royal Academy of Engineering, 2012). Without following these principles, which are outlined in the following, it is difficult to implement a smart infrastructure project.

(a) Acquire data: According to the Royal Academy of Engineering (2012), data are at the heart of all smart technology. To implement a smart infrastructure initiative, a process for acquiring data must be put in place, often times through the use of sensors. It is the acquired data that eventually form the basis for improved decision making (Fang et al., 2012).

(b) Analyse data: Once acquired, data must be processed, interpreted and transformed into an actionable format for optimised decision making with machine learning algorithms (Royal Academy of Engineering, 2012).

(c) Maintain feedback loop: A distinguishing characteristic of a smart infrastructure is its adaptive feature, which must be preserved by maintaining a feedback loop wherein acquired information about the infrastructure usage, performance and environmental conditions are constantly being used to optimise operational efficiency (Fang et al., 2012; Royal Academy of Engineering, 2012).

(d) Design for adaptability: In designing a smart infrastructure, adaptive capabilities must be built into the physical and digital components of the system in order to allow for real-time reconfiguration and adjustment to varying demands and environmental conditions (Annaswamy et al., 2016; Royal Academy of Engineering, 2012).

Extending from the discussions so far, a comprehensive definition of smart infrastructure is presented in the following.

Smart infrastructure can be defined as an infrastructure that integrates digital technology and (a) delivers the values of self-monitoring and accuracy in decision making; efficiency and cost savings; reliability; security, safety and resilience; user interaction and empowerment; sustainability; redundancy minimisation; fast response time; low carbon footprint; and service quality; $(b)$ functions based on the principles of data acquisition, data analysis, maintenance of feedback loop and design for adaptability; and (c) operates at higher levels from semi-intelligent infrastructures and intelligent/semismart infrastructure. 
Smart infrastructure: an emerging

frontier for multidisciplinary research

Ogie, Perez and Dignum

\section{Multidisciplinary approach to smart infrastructure}

Smart infrastructure is a fast-burgeoning industry, and its many dimensions as synthesised from literature indicate that a multidisciplinary approach will be required going forward. Since the last decade, the industry has gained significantly from academic research mainly focusing on installation of monitoring sensor networks in large-scale infrastructure systems such as bridges, rail tunnels, highways and water-supply pipelines (Bennett et al., 2010a; 2010b; Cheung et al., 2010; Hoult et al., 2009; Kim et al., 2007; Stajano et al., 2010; Stoianov et al., 2007). While these high-performing digital retrofit solutions have been mainly accomplished by teams of (civil and structural) engineers, broadranging impacts and accelerated progress in the smart infrastructure industry will depend on the adoption of multidisciplinary perspectives in future work. For example, data fusion researchers will play a crucial role in providing the techniques and designs that are most appropriate for integrating disparate data from multiple sensor nodes in order to present infrastructure operators with consistent, accurate and useful information for improving decision making (El-Diraby, 2003). Urban planning experts and researchers can contribute to the design of smart infrastructure, often considered a key component of smart city, in such a manner as to complement fully other elements of a smart city, such as smart operation, smart service and smart industry (Hao et al., 2012).

This multidisciplinary nature of smart infrastructure research is becoming more evident (Chu et al., 2012). Researchers outside the field of civil and structural engineering have begun to make interesting contributions by proposing ontologies, generic models and technical requirements for designing smart infrastructures (Chu et al., 2012; Spieß et al., 2007). Discussing from a technical viewpoint, Liu and Tomizuka (2003) noted that collaborative research focusing on smart infrastructure will require expert inputs from a wide range of disciplines, including AI, structural engineering, wireless communication, computer science, manufacturing, network systems, automation and control engineering, power electronics and Memss. More specifically, this multidisciplinary technical team would need to work closely together to put forward cost-effective designs that address several constraints militating against the realisation of the values and principles of smart infrastructure, discussed in Section 2.3. These constraints include network connectivity issues, fault tolerance, mismatch between the lifetime of embedded sensors and those of the actual physical infrastructure, scalability, accessibility, hardware limitations, optimal network topology or configuration, signal-tonoise enhancement, self-recalibration and reconfiguration of sensors, short-term and long-term monitoring needs, durable packaging and fabrication, timely and comprehensive presentation of data to decision makers and the maximisation of the time between battery replacements as specified by industry standards (Hosni and Hamdi, 2016; Hoult et al., 2009; Liu and Tomizuka, 2003; Royal Academy of Engineering, 2012).

Moreover, at the intersection of smart infrastructure and energy, there are strong grounds for multidisciplinary research. For example, economists could contribute to understand the degree to which the use of smart infrastructure (e.g. smart grids) can elasticise consumers' demand to better match the supply of electrical energy (Weiss, 2009). With several countries now putting smart infrastructure at the core of their energy policies, multidisciplinary research is needed to understand how the investment and construction of smart infrastructure such as smart grids impacts national policies and vice versa (Budde, 2014). Similarly, in an era where smart infrastructure is fast becoming a keystone for achieving energy efficiency, there is a greater need to work with environmental researchers in an effort to attain cleaner and greener environment, while also maximising opportunities for countries to meet their emission reduction goals (Clements et al., 2010). Clearly, the importance of achieving a low carbon footprint, being one of values of smart infrastructure, cannot be overemphasised. According to Smarr (2010), a worldwide effort in replacing traditional urban infrastructure with smart infrastructure can potentially achieve a reduction in global GHG emissions of up to $15 \%$ by 2020 .

Furthermore, with the world getting increasingly instrumented and interconnected, and smart infrastructure becoming the basis for nations, regions and cities to compete for economic activities, there is a need for greater participation from the business community in the co-development of business models to take full advantage of the global opportunities in this burgeoning industry that is worth $£ 2-4 \cdot 8$ trillion (CSIC, 2016a; Jackson, 2009; Xu, 2012). One pressing issue, though, that is limiting commercial investment in smart infrastructure is the challenge of putting forward a strong business case with robust cost-benefit analysis covering the entire asset life cycle and justifiable with financial data from real-world case studies (CSIC, 2016a). In any case, the issue remains that the payback for investing in smart infrastructure is not always clearcut (Royal Academy of Engineering, 2012). Accurately monetising the benefits that smart infrastructure provides to citizens and the society at large, in terms of improving quality of life, social outcomes, economic productivity, environmental outcomes, cost savings and government services is an increasingly complex task (Sanseverino et al., 2015). Unfortunately, traditional methods of proving return on investment fail to adequately account for the complexity of infrastructure systems, particularly over the asset lifetime, which could be as long as 50-100 years (Royal Academy of Engineering, 2012). To address this issue, the Royal Academy of Engineering (2012) emphasised the need to work together and integrate ideas from multidisciplinary perspectives in order to develop new ways of measuring value in smart infrastructure, possibly triggering changes to industry structure. The task of measuring the values of smart infrastructure, discussed in Section 2.3.2, can be daunting. Fresh insights could build on existing contributions such as the analysis put forward by Morimoto (2013) that involves the use of Monte Carlo simulation to understand the socio-economic impact of applying smart infrastructure sensor technology to the British rail tunnel industry. The study found that the estimated average value of the cumulative net present value for embarking on such investment is US\$40 million until the year 2056 (Morimoto, 2013). 
Smart Infrastructure and Construction

Volume 170 Issue SC1
Smart infrastructure: an emerging

frontier for multidisciplinary research

Ogie, Perez and Dignum
Also, with growing concerns and reports about cyberattacks on smart grids, there is never a better time to maximise the skills of security experts when designing smart infrastructures (Weiss, 2009). These smart infrastructures are increasingly becoming digitally sophisticated and highly reliant on computerised controls that are exploitable by hackers who want to cause service disruption or system compromise (Weiss, 2009). The huge cost, political influence and bureaucratic processes often associated with state investment in smart infrastructure also means that these infrastructures are built-in phases over a long period of time, even as technology is rapidly changing (Weiss, 2009). The direct result is the emergence of a heterogeneous patchwork of interconnected and interdependent infrastructure systems, with many local- and regional-level utility providers (Weiss, 2009). This situation complicates the task of securing smart urban infrastructure because of the need to satisfy interoperable technologies and to ensure all infrastructure providers meet the same minimum set of security standards (Weiss, 2009). Cybersecurity practitioners and researchers can contribute to understand these issues better.

In addition, these security specialists can provide the needed expertise to understand the unique and constantly evolving vulnerabilities in smart infrastructure networks (e.g. Stuxnet, Flame and other malware) so that security and resilience can be built into systems in a manner that allows for future upgrades (Royal Academy of Engineering, 2012). Security, safety and resilience together form one of the values of smart infrastructure, previously discussed in Section 2.3.2. Annaswamy et al. (2016) emphasised the need for more effort in achieving this value, stating that the cyberphysical security of smart infrastructures is still very much at an early stage of research. CSIC (2016a) added that improved security is one of the pressing issues that need to be addressed to enable the smart infrastructure industry to forge ahead. Importantly, control systems in smart infrastructure require specific cybersecurity technologies (Amin, 2010). According to Amin (2010: p. 2), 'the cyber security technologies developed for internet applications such as firewalls and intrusion detection systems may not perform as expected for control systems'. Cybersecurity should therefore be properly tailored and captured as functional rather than as non-functional requirements when designing such cyber-dependent smart infrastructures (Bayuk and Mostashari, 2011). In furtherance to the work of Bayuk and Mostashari (2011) on customising security metrics for smart infrastructure, there is a need to establish consistent and replicable industry guidelines for comparatively assessing different aspects of the security of smart urban infrastructure. The aforementioned tasks will require the expertise of cybersecurity professionals and researchers, further adding a new dimension to the multidisciplinary nature of constructing and maintaining smart infrastructure.

Smart infrastructure and associated safety issues form another reason to advocate for a multidisciplinary approach in designing such autonomous machines. No doubt, smart infrastructure is great in delivering desirable societal outcomes, but past events have shown that there is often a safety risk that may materialise down the track when human intelligence, often subject to mistakes, is offloaded into circuitry and when machines are allowed to take control of decision making (Weiss, 2009). According to Weiss (2009), the Washington, DC, metro train crash that killed nine commuters on 23 June 2009 and the Air France commercial jet crash that claimed all 228 lives on-board are two high-profile examples of safety issues associated with heavy reliance on computerised control. But who should be blamed for such errors in decisions made by so-called smart machines? What level of autonomy or control should be given to smart infrastructures that are used by humans and in what circumstances? These issues are of immense concern to society and transcend the technical boundaries of engineers responsible for designing and constructing smart infrastructures. The design of autonomous infrastructure systems should therefore be subjected to multidisciplinary scrutiny, having several dimensions including safety, privacy, legal, ethical and moral views.

Importantly, smart infrastructures have unique and profound ethics concerns. Smart infrastructures provide important services and goods to many different stakeholders and users, all of which hold different value perspectives (Aldewereld et al., 2015). At the same time, the design and construction of these infrastructures is an exercise that is relatively invisible to those affected by them; therefore, the values built into the systems are often not explicitly formulated nor evaluated (Manders-Huits and van den Hoven, 2009). Smart infrastructures aim to integrate solutions that simultaneously integrate values such as privacy, sustainability, efficiency and safety. However, in the not-so-ideal world people live in, there are many instances in which these value commitments can simply not all be satisfied at the same time, leading to "moral overload' (Van den Hoven et al., 2012). This means that thinking in an early stage of smart infrastructure design about relevant social and moral values, and the weaving of those into the intelligence fabrics or self-awareness of smart infrastructures, is an important step in satisfying the growing expectations of infrastructure stakeholders as well as regulatory requirements. Just recently, the EU adopted the General Data Protection Regulation, which might possibly include a 'right to an explanation' for algorithmic decisions made by machines when the regulation eventually takes effect as law across the EU in 2018 (Goodman and Flaxman, 2016). This demand for efficient, transparent and fair algorithm designs will potentially force engineers responsible for constructing smart urban infrastructure systems to treat their products not just as mere technical artefacts, but as ethical, moral machines that require multidisciplinary coordination between technical and philosophical resources of the highest calibre (Goodman and Flaxman, 2016).

\section{Conclusion}

The term 'smart infrastructure' has been used severally within different contexts in the literature, in many cases without a proper definition. This creates ambiguity, fragmentation and confusion that is unhealthy for research progress. Drawing primarily from academic and grey literature, this study has provided a comprehensive account of what it means for an infrastructure to be smart and how that is different from an intelligent infrastructure. Importantly, the paper introduces the LVPs of smart infrastructure to help create shared meaning and expectation from smart 
Smart infrastructure: an emerging

frontier for multidisciplinary research

Ogie, Perez and Dignum infrastructure initiatives. Finally, the multidisciplinary dimensions of smart infrastructure were discussed, with a clear direction on areas in which other professions can contribute. It is hoped that by eliminating ambiguity, fragmentation and the lack of clarity in the definition of smart infrastructure, this paper will facilitate accelerated progress in research and practice.

\section{REFERENCES}

Aktan AE, Helmicki AJ and Hunt VJ (1998) Issues in health monitoring for intelligent infrastructure. Smart Materials and Structures 7(5): 674-692.

Aldewereld H, Dignum V and Tan YH (2015) Design for values information and communication technologies in software development. In Handbook of Ethics, Values, and Technological Design: Sources, Theory, Values and Application Domains (van den Hoven J, Vermaas PE and van de Poel I (eds)). Springer, Dordrecht, the Netherlands, pp. 831-845.

Alkandari A, Alnasheet M and Alshaikhli IFT (2012) Smart cities: a survey. Journal of Advanced Computer Science and Technology Research (JACSTR) 2(2): 79-90.

Alusi A, Eccles RG, Edmondson AC and Zuzul T (2011) Sustainable Cities: Oxymoron or the Shape of the Future? Harvard Business School, Boston, MA, USA, Harvard Business School Organizational Behavior Unit Working Paper 11-062.

Amin SM (2010) Electricity infrastructure security: toward reliable, resilient and secure cyber-physical power and energy systems. In Institute of Electrical and Electronics (IEEE) PES General Meeting. IEEE, New York, NY, USA, pp. 1-5.

Annaswamy AM, Malekpour AR and Baros S (2016) Emerging research topics in control for smart infrastructures. Annual Reviews in Control 42: 259-270, http://dx.doi.org/10.1016/j.arcontrol.2016.10.001.

Balakrishna C (2012) Enabling technologies for smart city services and applications. In 2012 Sixth International Conference on Next Generation Mobile Applications, Services and Technologies. IEEE, New York, NY, USA, pp. 223-227.

Bayuk JL and Mostashari A (2011) Measuring cyber security in intelligent urban infrastructure systems. In 2011 8th International Conference \& Expo on Emerging Technologies for a Smarter World (CEWIT). IEEE, New York, NY, USA, pp. 1-6.

Bennett PJ, Kobayashi Y, Soga K and Wright P (2010a) Wireless sensor network for monitoring transport tunnels. Proceedings of the Institution of Civil Engineers - Geotechnical Engineering 163(3): 147-156, http://dx.doi.org/10.1680/geng.2010.163.3.147.

Bennett PJ, Soga K, Wassell I et al. (2010b) Wireless sensor networks for underground railway applications: case studies in Prague and London. Smart Structures and Systems 6(5-6): 619-639.

Buckman AH, Mayfield M and Beck SBM (2014) What is a smart building? Smart and Sustainable Built Environment 3(2): 92-109.

Budde P (2014) Smart cities of tomorrow. In Cities for Smart Environmental and Energy Futures (Rassia STh and Pardalos PM (eds)). Springer, Berlin, Germany, pp. 9-20, http://dx.doi.org/10. 1007/978-3-642-37661-0 2

Burgy C and Garrett JH (2002) Wearable computers: an interface between humans and smart infrastructure systems. VDI-Berichte 1668: 385-398.

Cheung LLK, Soga K, Bennett PJ et al. (2010) Optical fibre strain measurement for tunnel lining monitoring. Proceedings of the Institution of Civil Engineers - Geotechnical Engineering 163(3): 119-130, http://dx.doi.org/10.1680/geng.2010.163.3.119.

Chu T, Wang J and Leckie JO (2012) An ontology-based service model for smart infrastructure design. In 2012 International Conference on Cloud and Service Computing (CSC). IEEE, New York, NY, USA, pp. 17-24.

Clements T, D'Amato V and Taylor T (2010) Integrating water infrastructure in a new paradigm for sustainable, resilient communities. Proceedings of the Water Environment Federation 2010(2): 801-825.
CSIC (Cambridge Centre for Smart Infrastructure and Construction) (2016a) Smart Infrastructure: Getting More from Strategic Assets. CSIC, Cambridge, UK. See http://www-smartinfrastructure.eng. cam.ac.uk/files/the-smart-infrastructure-paper (accessed 25/11/2016).

CSIC (2016b) Introduction to CSIC. CSIC, Cambridge, UK. See http:// www-smartinfrastructure.eng.cam.ac.uk/files/introduction-to-csicpresentation-jms-for-asset-management-workshop (accessed 25/11/2016).

Dadashi N, Wilson JR, Sharples S, Golightly D and Clarke T (2011) A framework of data processing for decision making in railway intelligent infrastructure. In 2011 IEEE International Multidisciplinary Conference on Cognitive Methods in Situation Awareness and Decision Support (CogSIMA). IEEE, New York, NY, USA, pp. 276-283.

Dillon T, Potdar V, Singh J and Talevski A (2011) Cyber-physical systems: providing Quality of Service (QoS) in a heterogeneous systems-of-systems environment. In 5th IEEE International Conference on Digital Ecosystems and Technologies (IEEE DEST 2011). IEEE, New York, NY, USA, pp. 330-335.

El-Diraby TE (2003) A framework for integrated data management in smart infrastructure systems. In Construction Research Congress: Wind of Change: Integration and Innovation. American Society of Civil Engineers, Reston, VA, USA, pp. 1-8.

El-Diraby TE and Rasic I (2004) Framework for managing life-cycle cost of smart infrastructure systems. Journal of Computing in Civil Engineering 18(2): 115-119.

Elmenreich W and Egarter D (2012) Design guidelines for smart appliances. In Intelligent Solutions in Embedded Systems (WISES), 2012 Proceedings of the Tenth Workshop on. IEEE, New York, NY, USA, pp. 76-82.

Engineers Australia (2015) https://www.engineersaustralia.org.au/sites/ default/files/shado/Resources/smart_infrastructure.pdf (accessed 25/11/2016)

Fang X, Misra S, Xue G and Yang D (2012) Smart grid - the new and improved power grid: a survey. IEEE Communications Surveys \& Tutorials 14(4): 944-980.

Feng MQ, Suzuki H and Yokoi I (1995) Development of optical sensing systems for smart civil infrastructure. Smart Materials and Structures 4(1A): A114-A120.

Fujii T, Ohta M and Endo T (2013) High efficient multiple sensing information gathering for wireless sensor networks. In 2013 Fifth International Conference on Ubiquitous and Future Networks (ICUFN). IEEE, New York, NY, USA, pp. 202-207.

Gershenfeld N, Samouhos S and Nordman B (2010) Intelligent infrastructure for energy efficiency. Science 327(5969): 1086-1088.

Gibson DV and Stiles C (2000) Technopolis, technology transfer, and globally networked entrepreneurship. In Science, Technology and Innovation Policy: Opportunities and Challenges for the Knowledge Economy (Conceição P (ed.)). Quorum Books, Westport, CT, USA, pp. 195-207.

Goodman B and Flaxman S (2016) European Union regulations on algorithmic decision-making and a 'right to explanation'. In 2016 ICML Workshop on Human Interpretability in Machine Learning (WHI 2016). New York, NY, USA, arXiv preprint arXiv:1606.08813, pp. 1-9.

Guizani M and Anan M (2014) Smart grid opportunities and challenges of integrating renewable sources: a survey. In 2014 International Wireless Communications and Mobile Computing Conference (IWCMC). IEEE, New York, NY, USA, pp. 1098-1105.

Hagen A (2011) Exploring Support Infrastructures for Freight Transport Operations. PhD thesis, Department of Logistics and Transportation, Chalmers University of Technology, Gothenburg, Sweden.

Hao L, Lei X, Yan Z and ChunLi Y (2012) The application and implementation research of smart city in China. In 2012 International Conference on System Science and Engineering (ICSSE0). IEEE, New York, NY, USA, pp. 288-292. 
Smart Infrastructure and Construction

Volume 170 Issue SC1
Smart infrastructure: an emerging

frontier for multidisciplinary research

Ogie, Perez and Dignum
Hosni I and Hamdi N (2016) Identified improvements of wireless sensor networks in smart grid: issues, requirements and challenges. International Journal of Smart Grid and Green Communications 1(1): 3-37.

Hoult N, Bennett PJ, Stoianov I et al. (2009) Wireless sensor networks: creating 'smart infrastructure'. Proceedings of the Institution of Civil Engineers - Civil Engineering 162(3): 136-143, http://dx.doi.org/10. 1680/cien.2009.162.3.136.

Hoy MB (2016) Smart buildings: an introduction to the library of the future. Medical Reference Services Quarterly 35(3): 326-331.

Jackson A (2009) ICT and the new global investment paradigm: challenges to crossborder trade and investment. World Customs Journal 3(1): 55-61.

Kadam AW (2013) Governance and management of intelligent infrastructure. International Conference on Intelligent Infrastructure, Computer Society of India, Kolkata, India, pp. 1-5.

Kim S, Pakzad S, Culler D et al. (2007) Health monitoring of civil infrastructures using wireless sensor networks. In 2007 6th International Symposium on Information Processing in Sensor Networks. IEEE, New York, NY, USA, pp. 254-263.

Klar A, Levenberg E, Tur M and Zadok A (2016) Sensing for smart infrastructure: prospective engineering applications. International Conference on Smart Infrastructure and Construction (ICSIC), Cambridge, UK, 27-29 June, pp. 289-295.

Le HV, Nishio M, Yamada H and Katsuchi H (2015) Statistical condition assessment of a cable stayed bridge using GPS structural health monitoring data. 7th International Conference on Structural Health Monitoring of Intelligent Infrastructure, SHMII 2015, Turin, Italy, pp. $1-4$.

Lee SK and Gibson DV (2002) Towards knowledge-based economy in Korea: metrics and policy. International Journal of Technology, Policy and Management 2(3): 301-314.

Li YJ (2010) An overview of the DSRC/WAVE technology. International Conference on Heterogeneous Networking for Quality, Reliability, Security and Robustness, Springer, Berlin, Germany, pp. 544-558

Liu SC and Tomizuka M (2003) Vision and strategy for sensors and smart structures technology research. Proceedings of the 4th International Workshop on Structural Health Monitoring. Stanford, CA, USA, pp. 42-52.

Liu Y, Wei J and Rodriguez AFC (2014) Development of a strategic value assessment model for smart city. International Journal of Mobile Communications 12(4): 346-359.

Manders-Huits N and van den Hoven J (2009) The need for a valuesensitive design of communication infrastructures. In Evaluating New Technologies (Manders-Huits N and van den Hoven J (eds)). Springer, Dordrecht, the Netherlands, pp. 51-60.

Morimoto R (2010) Estimating the benefits of effectively and proactively maintaining infrastructure with the innovative smart infrastructure sensor system. Socio-economic Planning Sciences 44(4): 247-257.

Morimoto R (2013) A socio-economic analysis of Smart Infrastructure sensor technology. Transportation Research Part C: Emerging Technologies 31: 18-29, http://dx.doi.org/10.1016/j.trc.2013.02.015.

Negrete-Martínez J (2008) Paradigms behind a discussion on artificial intelligent/smart systems. In Toward Artificial Sapience (Mayorga RV and Perlovsky LI (eds)). Springer, London, UK, pp. 201-205.

Prasad R and Ruggieri M (2014) Special issue on 'intelligent infrastructure'. Wireless Personal Communications 76(2): 121-124.

Raluca BM (2013) Social capital framework and its influence on the entrepreneurial activity. Annals of the University of Oradea, Economic Science Series 22(1): 581-589.

Rice JA, Mechitov K, Sim SH et al. (2010) Flexible smart sensor framework for autonomous structural health monitoring. Smart structures and Systems 6(5-6): 423-438.

Royal Academy of Engineering (2012) Smart Infrastructure: the Future. Royal Academy of Engineering, London, UK. See http://www.raeng. org.uk/publications/reports/smart-infrastructure-the-future (accessed $25 / 11 / 2016)$
Sanseverino ER, Scaccianoce G, Vaccaro V, Zizzo G and Pennisi S (2015) Smart city and public lighting. In 2015 IEEE 15th International Conference on Environment and Electrical Engineering (EEEIC), IEEE, New York, NY, USA, pp. 665-670.

Shahzadi I, Amin S and Chaudhary KM (2013) drivers of supply chain performance enhancing organizational output: an exploratory study for manufacturing sector. Facilities Management 5(14): 53-64.

Smarr L (2010) Project Greenlight: optimizing cyber-infrastructure for a carbon-constrained world. Computer 43(1): 22-27.

Spieß P, Bornhövd C, Lin T, Haller S and Schaper J (2007) Going beyond auto-ID: a service-oriented smart items infrastructure. Journal of Enterprise Information Management 20(3): 356-370.

Stajano F, Hoult N, Wassell I et al. (2010) Smart bridges, smart tunnels: transforming wireless sensor networks from research prototypes into robust engineering infrastructure. Ad Hoc Networks 8(8): 872-888.

Stefansson G and Lumsden K (2008) Performance issues of smart transportation management systems. International Journal of Productivity and Performance Management 58(1): 55-70.

Stoianov I, Nachman L, Madden S and Tokmouline T (2007) PIPENET: a wireless sensor network for pipeline monitoring. In 2007 6th International Symposium on Information Processing in Sensor Networks. IEEE, New York, NY, USA, pp. 264-273.

Van den Hoven J, Lokhorst GJ and Van de Poel I (2012) Engineering and the problem of moral overload. Science and Engineering Ethics 18(1): $143-155$.

Venkatasubramanian KK, Mukherjee T and Gupta SK (2014) CAAC - an adaptive and proactive access control approach for emergencies in smart infrastructures. ACM Transactions on Autonomous and Adaptive Systems (TAAS) 8(4): 1-20.

Weiss A (2009) Smart infrastructure matches supply and demand. Networker 13(3): 18-25.

Wu Z and Fujino Y (2005) Structural health monitoring and intelligent infrastructure. Smart Materials and Structures 14(3): 1-2.

Xu X (2012) Internet of things in service innovation. Amfiteatru Economic 14(6): 698-719.

\section{How can you contribute?}

To discuss this paper, please email up to 500 words to the editor at journals@ice.org.uk. Your contribution will be forwarded to the author(s) for a reply and, if considered appropriate by the editorial board, it will be published as discussion in a future issue of the journal.

Proceedings journals rely entirely on contributions from the civil engineering profession (and allied disciplines). Information about how to email your paper online is available at www.icevirtuallibrary.com/page/authors, where you will also find detailed author guidelines. 